\title{
Medical resource utilization in dermatomyositis/ polymyositis patients treated with repository corticotropin injection, intravenous immunoglobulin, and/or rituximab
}

\author{
This article was published in the following Dove Press journal: \\ ClinicoEconomics and Outcomes Research \\ 16 May 2017 \\ Number of times this article has been viewed
}

Tyler Knight'

T Christopher Bond'

Breanna Popelar ${ }^{2}$

Li Wang ${ }^{3}$

John W Niewoehner ${ }^{4}$

Kathryn Anastassopoulos'

Michael Philbin ${ }^{4}$

'Covance Market Access Services Inc., Gaithersburg, MD, ${ }^{2}$ Xcenda, LLC, Palm Harbor, FL, ${ }^{3}$ STATinMED Research, Ann Arbor, MI, ${ }^{4}$ Mallinckrodt, LLC, Hazelwood, MO, USA
Correspondence: Tyler Knight Covance Market Access Services Inc., 9801 Washingtonian Blvd, 9th Floor, Gaithersburg, MD, 20878, USA

$\mathrm{Tel}+\mathrm{I} 3177389068$

Fax +I 2406323335

Email tyler.knight@covance.com
Background: Dermatomyositis and polymyositis (DM/PM) are rare, incurable inflammatory diseases that cause progressive muscle weakness and can be associated with increased medical resource use (MRU). When corticosteroid treatment is unsuccessful, patients may receive intravenous immunoglobulin (IVIg), rituximab, or repository corticotropin injection (RCI). This study compared real-world, non-medication MRU between patients treated with RCI and those treated with IVIg and/or rituximab for DM/PM.

Methods: Claims of DM/PM patients were analyzed from the combination of three commercial health insurance databases in the United States from July 2009 to June 2014. Patients treated with RCI were propensity score matched to those treated with IVIg, rituximab, and both (IVIg+rituximab) based on demographics, prior clinical characteristics, and prior MRU. Per-patient per-month (PPPM) MRU and costs were compared using Poisson regression and generalized linear modeling, respectively.

Results: One-hundred thirty-two RCI, 1,150 IVIg, and 562 rituximab patients had an average age of 52.6, 46.6, and 51.7 years, respectively, and roughly two-thirds were female. After matching, there were no significant differences in demographics or prior clinical characteristics. RCI patients had fewer PPPM hospitalizations ( 0.09 vs $0.17 ; P=0.049)$, shorter length of stay (LOS; 3.24 days vs 4.55 days; $P=0.004$ ), PPPM hospital outpatient department (HOPD) visits ( 0.60 vs $1.39 ; P<0.001)$, and PPPM physician office visits $(2.01$ vs $2.33 ; P=0.035)$ than IVIg. RCI had fewer PPPM HOPD visits $(0.56$ vs $0.92 ; P<0.001)$ than rituximab. Patients treated with RCI had shorter LOS (2.18 days vs $5.15 ; P<0.001)$ and less PPPM HOPD visits ( 0.53 vs 1.26 ; $P<0.001)$ than IVIg+rituximab. Total non-medication PPPM costs were $23 \%-75 \%$ lower for RCI compared to IVIg ( $\$ 2,126$ vs $\$ 3,964 ; P<0.001)$, rituximab ( $\$ 2,008$ vs $\$ 2,607 ; P=0.018)$, and IVIg+rituximab $(\$ 1,234$ vs $\$ 4,858 ; P<0.001)$.

Conclusion: Patients treated with RCI had less PPPM non-medication MRU and costs than those treated with IVIg and/or rituximab, particularly in the hospital setting where significant costs are incurred.

Keywords: dermatomyositis, polymyositis, resource, costs, adrenocorticotropic hormone

\section{Introduction}

Dermatomyositis (DM) and polymyositis (PM) are rare inflammatory diseases that cause progressive muscle weakness, usually in the neck, upper arms, hips, and thighs. ${ }^{1,2}$ $\mathrm{DM} / \mathrm{PM}$ can be associated with increased medical resource use (MRU) and productivity loss. ${ }^{3}$ These two diseases are often grouped together due to their shared clinical 
features; however, DM can also be associated with skin rash on the hands, feet, elbows, face, and/or upper body., Epidemiology studies have estimated the combined annual incidence of DM/PM to be two per 100,000 persons in the United States, ${ }^{5}$ with an overall prevalence that has been estimated as high as 22 per $100,000 .^{6}$

There is no cure for DM/PM, but certain treatments can improve muscle strength and function. ${ }^{7}$ Corticosteroids and corticosteroid-sparing agents are used early in the treatment paradigm to improve muscle function. DM/PM patients receiving corticosteroids are closely monitored, and their corticosteroid dose is typically tapered as quickly as possible. Corticosteroid treatment may be supplemented or replaced by immunosuppressants (e.g., methotrexate and azathioprine), which allows the patient to taper off corticosteroids more quickly to avoid side effects, but these agents may be associated with toxicity to the kidneys, liver, and bone marrow. ${ }^{8}$ When corticosteroid treatment is not successful in managing the disease and/or the side effects are not well tolerated, patients may receive second-line alternative treatments, including immunosuppressive drugs, intravenous immunoglobulin (IVIg), or biological therapies, such as rituximab ${ }^{9,10}$ all of which are off-label therapies. However, IVIg is not considered second-line for polymyositis, and the efficacy of rituximab has been shown to be no different from placebo in at least one clinical trial for the treatment of myositis. ${ }^{1-13}$ Furthermore, both IVIg and rituximab need to be administered by a health-care professional, typically in a physician office, outpatient infusion center, or a hospital. ${ }^{14-16}$ Outside of corticosteroids, the only United States Food and Drug Administration (FDA)-approved treatment for DM/PM is repository corticotropin injection (RCI; H.P. Acthar $^{\circledR}$ Gel; Mallinckrodt Pharmaceuticals, Hazelwood, MO, USA). ${ }^{7}$ Previous studies have shown RCI to be tolerated and effective in treating DM/PM in a limited number of patients. ${ }^{17,18}$

Despite not having FDA-approved indications, IVIg and rituximab are used to treat DM/PM patients. The objective of this retrospective observational database study was to compare real-world MRU and associated costs between patients treated with RCI and those treated with IVIg and/ or rituximab for $\mathrm{DM} / \mathrm{PM}$.

\section{Materials and methods}

\section{Data sources}

This study used de-identified administrative claims from three large sources (over 450 million covered lives across all three databases) over an observation period from July 1 ,
2009 to June 30, 2014. Duplicate patients from across the three databases were identified by a probabilistic algorithm using age, gender, region, admission date, discharge date, primary diagnosis, secondary diagnosis, and procedure codes so that patients were only counted one time. This study was approved by a central institutional review board, New England Independent Review Board (Needham, MA, USA), and further obtained waiver of informed consent as the research involved no more than minimal risk to the participants, and also the waiver did not adversely affect the rights and welfare of the participants.

\section{Study population}

Patients were included in the study if any of their administrative claims contained a primary International Classifications of Diseases, Ninth Revision, Clinical Modification $\left(\right.$ ICD9-CM) ${ }^{19}$ diagnosis code for DM (710.3) or PM (710.4), and were treated with RCI, an IVIg product, and/ or rituximab. RCI treatment was identified by a National Drug Codes (NDCs) of 63004773101 and 63004871001 on a pharmacy claim or Healthcare Common Procedure Coding System (HCPCS) code J0800 on a medical claim. Similarly, rituximab treatment was identified by NDCs 50242005306 and 50242005121 on a pharmacy claim and by HCPCS code $\mathrm{J} 9310$ on a medical claim. IVIg products were identified by HCPCS codes, J1572, J1561, J1459, J1569, J1556, J1557, J1566, J1568, and J1599, on a medical claim. Patients were divided into the following treatment cohorts:

1. RCI cohort: Patients with RCI on at least one medical or pharmacy claim between July 1, 2010 (1 year after the start of study observation period) and May 31, 2014 (1 month prior to the end of study observation period). These patients may or may not have received IVIg or rituximab at some point. This cohort definition was applied because, clinically, RCI is sometimes used as a later-line therapy than IVIg or rituximab.

2. Non-RCI cohorts: Patients with IVIg and/or rituximab on at least one medical or pharmacy claim between July 1 , 2010 (1 year after the start of study observation period) and May 31, 2014 (1 month prior to end of study observation period) and no claim for RCI over the entire study observation period (from July 1, 2009 to June 30, 2014):

1. IVIg cohort: Patients with an IVIg product on one or more claims

2. Rituximab cohort: Patients with rituximab on one or more claims 
3. IVIg+rituximab (IVIg+R) cohort: Patients with one or more claims for both an IVIg product and rituximab (note: this is a subset of patients in the IVIg and rituximab cohorts)

The cohorts were formed based on general clinical practice of using RCI as a later-line therapy. IVIg and rituximab were chosen as comparators to RCI because they could be used for more moderate-to-severe myositis without clinical response to previous DM/PM therapies over 2-3 months, ${ }^{20}$ and similar to RCI, are typically used as a second- or third-line treatment. Corticosteroids were not used as a comparative treatment because corticosteroid treatment is typically the first-line therapy; thus, those patients were assumed to not be as severe as those receiving RCI, IVIg, or rituximab.

Patients in the RCI, IVIg, and rituximab cohorts were required to have continuous eligibility for at least 1 year prior to receiving the first respective treatment and at least 30 days after the first respective treatment. Patients in the IVIg $+\mathrm{R}$ cohort were required to have continuous eligibility for at least 1 year prior to and at least 30 days after receiving treatment of the second of the two drugs, whichever came second.

\section{Analytic methods}

The first date of RCI, IVIg, or rituximab was used as the index date for patients in these respective cohorts. For patients in the IVIg+R cohort, date of the subsequent treatment was used as the index date. The pre-index period was the 1-year period prior to and including the index date. The post-index period included 1 year following any of the following: the index date, loss of eligibility, or the end of the study observation period (such as June 30, 2014), whichever occurred first.

Three sets of analyses were conducted to compare the RCI cohort to each of the other three cohorts. To account for underlying differences between the cohorts being compared, RCI patients were matched 1:3 to IVIg patients, $1: 3$ to rituximab patients, and 1:1 to IVIg+R patients in three separate matching algorithms. Propensity scores (such as probability of receiving $\mathrm{RCI}$ ) were calculated for each patient using a multivariate logistic regression analysis with the following covariates measured in the pre-index period: age, gender, history of cancer, previous treatment with corticosteroids (prednisone or methylprednisolone), azathioprine, methotrexate, or mycophenolate mofetil, comorbid conditions (assessed by Deyo's adapted Charlson Comorbidity Index, ${ }^{21}$ the Elixhauser Comorbidity Index score, ${ }^{22}$ and the Chronic
Disease $\operatorname{Score}^{23}$ ), the number of pre-index hospitalizations, and total pre-index costs (excluding DM/PM medications).

Propensity score matching was performed using a greedy propensity score algorithm without replacement. ${ }^{24} \mathrm{RCI}$ patients were matched with other patients by five digits of propensity score. Remaining unmatched patients were then matched by four digits, and the process continued through one-digit matches. For the requirement of 1:3 matching, each RCI patient required three matches to remain in the analysis. A 1:1 match was performed for the RCI and IVIg+R comparison due to limited sample size in the IVIg+R cohort.

\section{Analysis}

The following all-cause MRUs were identified during the post-index period from the administrative claims: number of hospitalizations, mean length of stay (LOS) per hospitalization, number of emergency room (ER) visits, number of hospital outpatient department (HOPD) visits, and number of physician office visits. Associated total visit costs (excludes all medications), hospitalization costs, and non-hospitalization visit costs were calculated from the reimbursement amounts reported on the administrative claims. Provider and patient out-of-pocket costs were not examined for this analysis. In order to maximize our study population, so that adequate sample sizes could be analyzed, per-patient per-month (PPPM) MRU and costs were calculated for each patient as the total MRU and costs divided by the number of months observed for that patient in the post-index period. A sensitivity analysis was conducted that censored all patients in each propensity score matched set (such as RCI vs IVIg: 1:3, RCI vs rituximab: $1: 3$, RCI vs IVIg+R: $1: 1)$ to the minimum follow-up time among the patients in that set.

Descriptive statistics on demographic and pre-index clinical characteristics of the cohorts were calculated before propensity score matching and after propensity score matching. All demographic and pre-index clinical variables were compared between cohorts by standard differences (STDdiff) before and after matching. A STDdiff $>10 \%$ was considered a significant difference. ${ }^{25}$

PPPM mean number of events for each type of MRU was compared between RCI and the other three cohorts with Poisson's regression using a generalized linear model with a $\log$ link. For events that occurred among $<15 \%$ of patients, a zero-inflated Poisson model was used. The mean hospital LOS, among patients with at least one hospitalization, was also examined using Poisson regression models. PPPM mean costs were compared between RCI and the other three cohorts using a generalized linear model with a gamma 
distribution and log link to account for the non-normality of the costs. Significance was set at an $\alpha$ of 0.05 . All analyses were performed using SAS Software, version 9.3 or higher (SAS Institute, Inc., Cary, NC, USA).

\section{Results}

A total of 53,102 patients with DM/PM were identified from the three combined claims data sources. Among these patients, $172(0.3 \%)$ were treated with RCI compared to $3,044(5.7 \%)$ who were treated with either IVIg and/or rituximab. Figure 1 presents cohort sizes after the eligibility criteria were applied ( $41 \%$ attrition), duplicate patients were removed ( $3 \%$ attrition), and cohorts were matched with propensity scores. This resulted in 132 patients in the RCI cohort (130 post match), 1,150 patients in the IVIg cohort (390 post match), 562 patients in the rituximab cohort (330 post match), and 123 in the IVIg+R cohort ( 87 post match). Of note, $30(22.7 \%)$ RCI patients had previous IVIg treatment, and 7 (5.3\%) RCI patients had previous rituximab treatment.

\section{Demographics and clinical characteristics}

Prior to matching, differences between the RCI cohort and the other three cohorts in the pre-index period were observed for age, cancer history, prior treatments, comorbidity scores, and pre-index MRU and costs (Table 1). Compared to the other cohorts, prior to matching, the RCI cohort differed significantly (STDdiff $\geq 10 \%$ ) for the following with

1. an average older age (52.6 years) than the IVIg (46.6 years) and IVIg+R cohorts (47.8 years);

2. a smaller proportion (15.9\%) with prior cancer than the IVIg (22.3\%), rituximab (27.2\%), and IVIg+R (27.6\%) cohorts;

3. a larger proportion (83.3\%) receiving prior treatment with corticosteroids than the IVIg (69.9\%) cohort

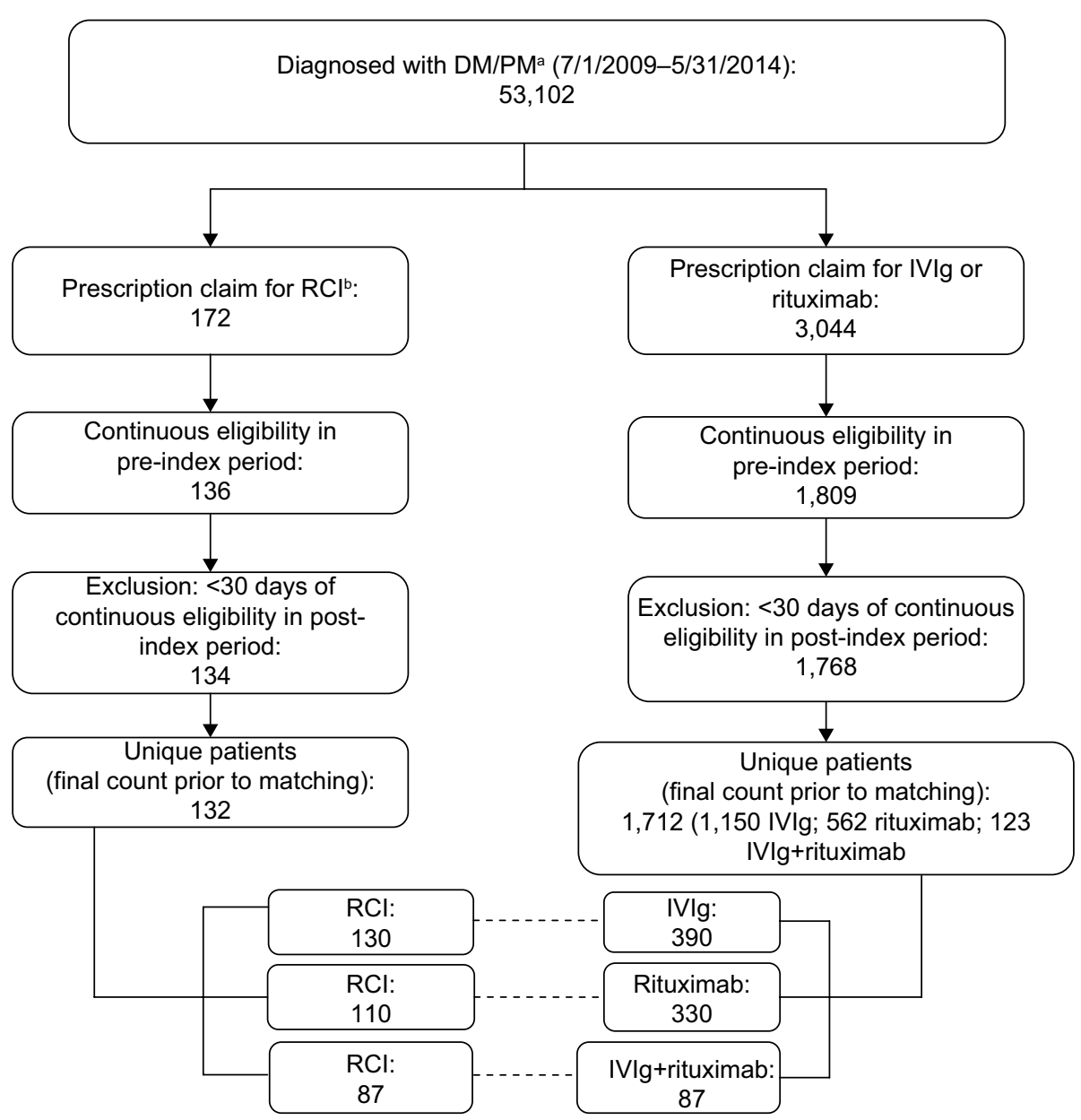

Figure I Patient attrition.

Notes: aCD-9-CM codes of 710.3 or 710.4 . ${ }^{\circ} \mathrm{RCl}$ is identified with patients having NDC codes of either 63004-773I-0I or 63004-87I0-0I or an HCPCS code for corticotropin injection (j0800).

Abbreviations: RCl, adrenocorticotropic hormone; DM, dermatomyositis; IVlg, intravenous immunoglobulin; PM, polymyositis; ICD-9-CM, International Classifications of Diseases, Ninth Revision, Clinical Modification; NDC, National Drug Codes; HCPCS, Healthcare Common Procedure Coding System. 
Table I Demographic and pre-index clinical characteristics prior to matching

\begin{tabular}{|c|c|c|c|c|c|c|c|}
\hline Characteristic & $\begin{array}{l}\mathrm{RCl} \\
(\mathrm{N}=132)\end{array}$ & $\begin{array}{l}\text { IVIg } \\
(N=I, I 50)\end{array}$ & $\begin{array}{l}\text { Rituximab } \\
(\mathrm{N}=562)\end{array}$ & $\begin{array}{l}\text { IVIg+ } \\
\text { rituximab } \\
(\mathrm{N}=\mid \mathbf{2 3})\end{array}$ & $\begin{array}{l}\text { RCI vs } \\
\text { IVIg } \\
\text { STDdiff }\end{array}$ & $\begin{array}{l}\text { RCl vs } \\
\text { rituximab } \\
\text { STDdiff }\end{array}$ & $\begin{array}{l}\text { RCI vs IVIg+ } \\
\text { rituximab } \\
\text { STDdiff }\end{array}$ \\
\hline Age (at index date), mean (SD) & $52.6(11.82)$ & $46.6(18.43)$ & $51.7(14.02)$ & $47.8(15.10)$ & 38.8 & 6.9 & 35.7 \\
\hline Female, n (\%) & $88(66.7)$ & $796(69.2)$ & $391(69.6)$ & 81 (65.9) & 5.5 & 6.2 & 1.7 \\
\hline Indication of cancer, n (\%) & $21(15.9)$ & $256(22.3)$ & $153(27.2)$ & $34(27.6)$ & 16.2 & 27.7 & 28.6 \\
\hline Prior DM/PM treatment, $\mathrm{n}(\%)$ & $121(9 \mid .7)$ & $885(77.0)$ & $516(91.8)$ & $114(92.7)$ & 41.2 & 0.5 & 3.8 \\
\hline $\begin{array}{l}\text { Prior corticosteroids (prednisone or } \\
\text { methylprednisolone), } n(\%)\end{array}$ & $110(83.3)$ & $804(69.9)$ & $502(89.3)$ & II $0(89.4)$ & 32.1 & 17.5 & 17.8 \\
\hline Prior azathioprine, n (\%) & $38(28.8)$ & $190(16.5)$ & $102(18.1)$ & $30(24.4)$ & 29.6 & 25.2 & 9.9 \\
\hline Prior methotrexate, n (\%) & $53(40.2)$ & $385(33.5)$ & $211(37.5)$ & $42(34.1)$ & 13.8 & 5.3 & 12.4 \\
\hline Prior MMF, n (\%) & $29(22.0)$ & $183(15.9)$ & $99(17.6)$ & $29(23.6)$ & 15.5 & 10.9 & 3.8 \\
\hline Deyo's adapted CCl score, mean (SD) & $1.9(1.58)$ & $1.8(1.94)$ & $2.2(2.07)$ & $2.3(2.45)$ & 8.4 & 14.0 & 17.0 \\
\hline Elixhauser Comorbidity Index score ( $\geq 2), n(\%)$ & $86(65.2)$ & $617(53.7)$ & $335(59.6)$ & $88(71.5)$ & 23.5 & 11.4 & 13.7 \\
\hline Chronic Disease Score, mean (SD) & $7.6(3.78)$ & $5.8(4.15)$ & $6.5(4.30)$ & $6.3(4.35)$ & 44.5 & 27.2 & 32.5 \\
\hline Pre-index number of hospitalizations, mean (SD) & $2.4(8.34)$ & $5.1(13.54)$ & $4.8(11.47)$ & $7.8(17.24)$ & 23.7 & 23.9 & 39.5 \\
\hline $\begin{array}{l}\text { Pre-index total costs (excluding DM/PM } \\
\text { medication costs), mean (SD) }\end{array}$ & $\begin{array}{l}35,970 \\
(46,591)\end{array}$ & $\begin{array}{l}55,195 \\
(92,041)\end{array}$ & $\begin{array}{l}\$ 42,798 \\
(\$ 75,189)\end{array}$ & $\begin{array}{l}\$ 71,535 \\
(\$ 119,312)\end{array}$ & 26.4 & 10.9 & 39.3 \\
\hline
\end{tabular}

Abbreviations: $\mathrm{CCl}$, Charlson Comorbidity Index; DM, dermatomyositis; IVIg, intravenous immunoglobulin; MMF, mycophenolate mofetil; PM, polymyositis; RCl, repository corticotropin injection; SD, standard deviation; STDiff, standard difference.

but smaller proportion than the rituximab $(89.3 \%)$ or IVIg+R (89.4\%) cohorts;

4. a larger proportion $(28.8 \%)$ receiving prior treatment with azathioprine than the IVIg (16.5\%) and rituximab $(18.2 \%)$ cohorts;

5. a larger proportion $(40.2 \%)$ receiving prior treatment with methotrexate than the IVIg (33.5\%) and IVIg+R (34.2\%) cohorts;

6. a larger proportion $(22.0 \%)$ receiving prior treatment with MMF than the IVIg (15.9\%) and rituximab (17.6\%) cohorts;

7. a lower average Deyo's adapted CCI score (1.9) than the rituximab (2.2) and IVIg+R (2.3) cohorts;

8. a larger proportion $(65.2 \%)$ of patients with an Elixhauser Comorbidity Index $\geq 2$ than the IVIg (53.7\%) and rituximab $(59.6 \%)$ cohorts, but smaller than the IVIg+R cohort $(71.5 \%)$;

9. a higher average Chronic Disease Score (7.6) than the IVIg (5.8), rituximab (6.5) and IVIg+R (6.3) cohorts;

10. fewer average pre-index hospitalizations (2.4) than the IVIg (5.1), rituximab (4.8), and IVIg+R (7.8) cohorts;

11. lower average total pre-index costs $(\$ 35,970)$ than the IVIg $(\$ 55,195)$, rituximab $(\$ 42,798)$, and IVIg+R $(\$ 71,535)$ cohorts.

After propensity score matching, there were no significant differences between RCI and any of the three other cohorts (STDdiff $<10 \%$ ) for all demographic and pre-index clinical characteristics compared (Table 2).

\section{Post-index MRU and costs}

In the post-index period, the RCI cohort had less MRU, on average, compared to the other three cohorts (Table 3). The RCI cohort had 47\% fewer PPPM hospitalizations compared to IVIg $(0.09$ vs $0.17 ; P=0.049)$ and $29 \%$ shorter LOS when hospitalized ( 3.2 days vs 4.6 days; $P=0.004$ ). A $58 \%$ shorter LOS was also observed in the RCI cohort compared to the IVIg+R cohort $(2.18$ days vs 5.15 days; $P<0.001)$. Additionally, the RCI cohort had 57\% fewer number of PPPM HOPD visits compared to the IVIg cohort ( 0.60 vs 1.39 ; $P<0.001$ ), and $39 \%$ and $58 \%$ fewer PPPM HOPD visits compared to the rituximab cohort ( 0.56 vs $0.92 ; P<0.001)$ and IVIg+R cohort ( 0.53 vs $1.26 ; P<0.0001)$, respectively. Finally, fewer PPPM physician office visits were observed among the RCI cohort compared to the IVIg cohort (2.01 vs $2.33 ; P=0.035)$. Other differences were not significant between cohorts $(P>0.05)$.

Average PPPM total visit costs associated with hospitalizations and non-hospitalizations in the post-index period also were significantly lower compared to the other three cohorts (Figure 2). Specifically, average total visit costs were significantly lower in the RCI cohort compared to IVIg $(\$ 2,126$ vs $\$ 3,964 ; P<0.001)$, rituximab $(\$ 2,008$ vs $\$ 2,607 ; P=0.018)$, and IVIg+R ( $\$ 1,234$ vs $\$ 4,858$; $P<0.001)$ cohorts. Both hospitalization costs $(\$ 874$ vs $\$ 1,764 ; P<0.001)$ and non-hospitalization visit costs $(\$ 1,252$ vs $\$ 2,200 ; P<0.001)$ were significantly lower in the RCI cohort when compared to IVIg. Non-hospitalization visit costs were significantly lower in the RCI 
Table 2 Demographic and pre-index clinical characteristics after matching

\begin{tabular}{|c|c|c|c|c|c|c|c|c|c|}
\hline \multirow[t]{2}{*}{ Characteristic $^{a}$} & \multicolumn{3}{|l|}{ RCI vs IVIg } & \multicolumn{3}{|c|}{$\mathrm{RCl}$ vs rituximab } & \multicolumn{3}{|c|}{ RCI vs IVIg+rituximab } \\
\hline & $\begin{array}{l}R C I \\
(N=\mid 30)\end{array}$ & $\begin{array}{l}\text { IVlg } \\
(N=390)\end{array}$ & $\begin{array}{l}\text { STDdiff } \\
\text { (\%) }\end{array}$ & $\begin{array}{l}\mathrm{RCl} \\
(\mathrm{N}=|| 0)\end{array}$ & $\begin{array}{l}\text { Rituximab } \\
(\mathbf{N}=330)\end{array}$ & $\begin{array}{l}\text { STDdiff } \\
\text { (\%) }\end{array}$ & $\begin{array}{l}\mathrm{RCl} \\
(\mathrm{N}=87)\end{array}$ & $\begin{array}{l}\mathrm{IVIg+} \\
\text { rituximab } \\
(\mathrm{N}=87)\end{array}$ & $\begin{array}{l}\text { STDdiff } \\
\text { (\%) }\end{array}$ \\
\hline Age (at index date), mean (SD) & $52.6(I I .8 I)$ & $52.7(14.15)$ & 1.4 & $52.9(12.26)$ & $52.1(14.00)$ & 6.1 & $50.8(11.91)$ & $50.3(13.68)$ & 4.4 \\
\hline Female, n (\%) & $87(66.9)$ & $257(65.9)$ & 2.2 & $75(68.2)$ & $227(68.8)$ & 1.3 & $57(65.5)$ & $54(62.1)$ & 7.1 \\
\hline Indication of cancer, n (\%) & $21(16.2)$ & $67(17.2)$ & 2.8 & $21(19.1)$ & $65(19.7)$ & 1.5 & $19(21.8)$ & I8 (20.7) & 2.8 \\
\hline Prior DM/PM treatment, $\mathrm{n}(\%)$ & $119(91.5)$ & $347(89.0)$ & 8.6 & $102(92.7)$ & $293(88.8)$ & 13.6 & $80(92.0)$ & $79(90.8)$ & 4.1 \\
\hline $\begin{array}{l}\text { Prior corticosteroids (prednisone } \\
\text { or methylprednisolone), } \mathrm{n}(\%)\end{array}$ & $108(83.1)$ & $329(84.4)$ & 3.5 & $99(90.0)$ & $287(87.0)$ & 9.5 & $74(85.1)$ & $75(86.2)$ & 3.3 \\
\hline Prior azathioprine, n (\%) & $36(27.7)$ & $92(23.6)$ & 9.4 & $25(22.7)$ & $62(18.8)$ & 9.7 & $25(28.7)$ & $23(26.4)$ & 5.1 \\
\hline Prior methotrexate, n (\%) & $52(40.0)$ & $150(38.5)$ & 3.1 & $46(4 I .8)$ & $135(40.9)$ & 1.8 & $32(36.8)$ & 33 (37.9) & 2.4 \\
\hline Prior MMF, n (\%) & $28(2 \mid .5)$ & $86(22.1)$ & 1.2 & $24(21.8)$ & $66(20.0)$ & 4.5 & $22(25.3)$ & $20(23.0)$ & 5.3 \\
\hline $\begin{array}{l}\text { Deyo's adapted CCl score, } \\
\text { mean (SD) }\end{array}$ & $1.9(1.59)$ & I.8 (I.73) & 4.2 & $2.0(1.66)$ & $2.0(1.78)$ & 2.1 & $1.9(1.74)$ & I.8 (I.49) & 8.5 \\
\hline $\begin{array}{l}\text { Elixhauser Comorbidity Index } \\
\text { score }(\geq 2), n(\%)\end{array}$ & $84(64.6)$ & $253(64.9)$ & 0.5 & 69 (62.7) & $198(60.0)$ & 5.6 & $62(7 \mid .3)$ & $62(7 \mid .3)$ & 0.0 \\
\hline $\begin{array}{l}\text { Chronic Disease Score, } \\
\text { mean (SD) }\end{array}$ & 7.5 (3.78) & $7.2(4.06)$ & 8.0 & $7.2(3.72)$ & $7.1(4.14)$ & 2.5 & $7.2(4.02)$ & $7.0(4.26)$ & 3.3 \\
\hline $\begin{array}{l}\text { Pre-index number of } \\
\text { hospitalizations, mean (SD) }\end{array}$ & $2.5(8.40)$ & $2.5(4.88)$ & 0.2 & $2.9(9.07)$ & $3.2(6.83)$ & 3.5 & $3.5(10.10)$ & $3.4(7.08)$ & I.I \\
\hline $\begin{array}{l}\text { Pre-index total costs (excluding } \\
\text { DM/PM medication costs), } \\
\text { mean (SD) }\end{array}$ & $\begin{array}{l}\$ 36,320 \\
(\$ 46,852)\end{array}$ & $\begin{array}{l}\$ 35,203 \\
(\$ 47,225)\end{array}$ & 2.4 & $\begin{array}{l}\$ 33,487 \\
(\$ 45,898)\end{array}$ & $\begin{array}{l}\$ 34,524 \\
(\$ 43,409)\end{array}$ & 2.3 & $\begin{array}{l}\$ 43,690 \\
(\$ 54,525)\end{array}$ & $\begin{array}{l}\$ 43,351 \\
(\$ 44,265)\end{array}$ & 0.7 \\
\hline
\end{tabular}

Note: aAll variables used in the propensity score matching used to match patients receiving $\mathrm{RCl}$ to those not receiving $\mathrm{RCl}$.

Abbreviations: $\mathrm{CCl}$, Charlson Comorbidity Index; DM, dermatomyositis; IVIg, intravenous immunoglobulin; MMF, mycophenolate mofetil; PM, polymyositis; RCl, repository corticotropin injection SD, standard deviation; STDiff, standard difference.

Table 3 Medical resource use in the post-index period

\begin{tabular}{|c|c|c|c|c|c|c|c|c|c|}
\hline & \multicolumn{3}{|c|}{ RCI vs IVIg } & \multicolumn{3}{|c|}{$\underline{\mathrm{RCl} \text { vs rituximab }}$} & \multicolumn{3}{|c|}{ RCI vs IVIg+R } \\
\hline & $\begin{array}{l}R C l \\
(N=130)\end{array}$ & $\begin{array}{l}\text { IVIg } \\
(\mathrm{N}=390)\end{array}$ & $P$-value ${ }^{a}$ & $\begin{array}{l}\mathrm{RCl} \\
(\mathrm{N}=\mid 10)\end{array}$ & $\begin{array}{l}\text { Rituximab } \\
(\mathbf{N}=330)\end{array}$ & $P$-value ${ }^{a}$ & $\mathrm{RCl}(\mathbf{N}=87)$ & $\begin{array}{l}\text { IVIg+R } \\
(\mathrm{N}=87)\end{array}$ & $P$-value ${ }^{a}$ \\
\hline \multicolumn{10}{|l|}{ Hospitalizations } \\
\hline n (\%) & $26(20.0)$ & $104(26.7)$ & & $22(20.0)$ & $101(30.6)$ & & $14(16.1)$ & $18(20.7)$ & \\
\hline Mean PPPM (SD) & $0.09(0.44)$ & $0.17(0.55)$ & $0.049^{*}$ & $0.10(0.48)$ & $0.16(0.54)$ & $0.128^{*}$ & $0.08(0.44)$ & $0.10(0.44)$ & $0.980^{*}$ \\
\hline LOS, mean (SD) ${ }^{\mathrm{b}}$ & $3.24(3.36)$ & $4.55(9.47)$ & 0.004 & $2.92(3.06)$ & 3.09 (3.79) & 0.690 & $2.18(1.53)$ & $5.15(8.47)$ & $<0.001^{*}$ \\
\hline \multicolumn{10}{|l|}{ ER visits } \\
\hline n (\%) & $27(20.8)$ & $95(24.4)$ & & $21(19.1)$ & 81 (24.6) & & $14(16.1)$ & $22(25.3)$ & \\
\hline Mean PPPM (SD) & $0.04(0.09)$ & $0.05(0.15)$ & 0.472 & $0.03(0.08)$ & $0.06(0.19)$ & $0.232^{*}$ & $0.03(0.09)$ & $0.06(0.15)$ & $0.500^{*}$ \\
\hline \multicolumn{10}{|l|}{ HOPD visits } \\
\hline n (\%) & 93 (7I.5) & $347(89.0)$ & & 78 (70.9) & $278(84.2)$ & & $51(58.6)$ & $76(87.4)$ & \\
\hline Mean PPPM (SD) & $0.60(0.92)$ & $1.39(1.73)$ & $<0.001^{*}$ & $0.56(0.89)$ & $0.92(1.12)$ & $<0.001^{*}$ & $0.53(0.93)$ & $1.26(1.60)$ & $<0.001^{*}$ \\
\hline \multicolumn{10}{|l|}{ Physician office visits } \\
\hline n (\%) & $128(98.5)$ & $383(98.2)$ & & $108(98.2)$ & $320(97.0)$ & & $75(86.2)$ & $86(98.9)$ & \\
\hline Mean PPPM (SD) & $2.01(1.73)$ & $2.33(1.82)$ & 0.035 & $1.94(1.64)$ & $2.06(1.69)$ & 0.473 & $1.70(1.82)$ & $2.07(1.55)$ & 0.589 \\
\hline
\end{tabular}

Notes: P-values are from a generalized linear model with Poisson's distribution and a log link specified. P-values with an asterisk (*) were calculated via a zero-inflated Poisson model due to the presence of $>15 \%$ observations with a value of 0 . ${ }^{b} A m o n g$ those patients who were hospitalized.

Abbreviations: RCl, repository corticotropin injection; ER, emergency room; HOPD, hospital outpatient department; IVlg, intravenous immunoglobulin; LOS, length of stay; MRU, medical resource utilization; SD, standard deviation; PPPM, per-patient per-month.

cohort compared to rituximab cohort $(\$ 1,076$ vs $\$ 1,614$; $P<0.001)$. Similar to IVIg, both hospitalization costs $(\$ 319$ vs $\$ 2,264 ; P<0.001)$ and non-hospitalization visit costs ( $\$ 915$ vs $\$ 2,594 ; P<0.001$ ) were significantly lower in the $\mathrm{RCI}$ cohort when compared to IVIg+R.

\section{Sensitivity analysis}

Average monthly patient follow-up times in the post-index period differed slightly across the cohorts. Although all results were reported as PPPM, a sensitivity analysis was performed to ensure that these results were consistent if 


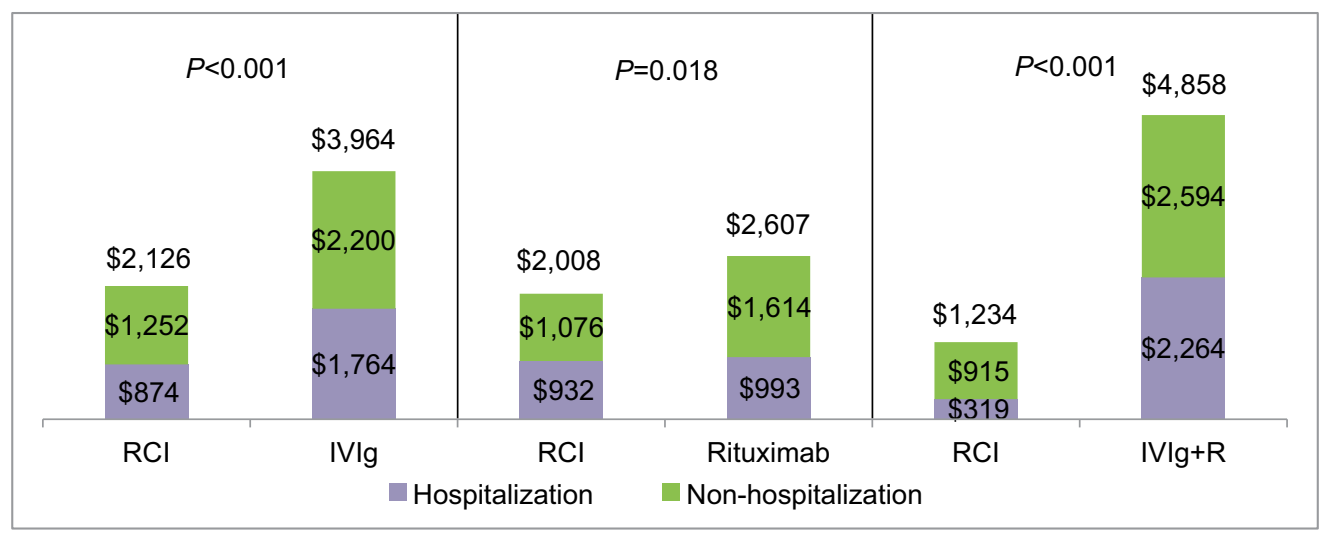

\begin{tabular}{|c|c|c|c|c|c|c|c|c|c|}
\hline \multirow[b]{2}{*}{$\begin{array}{l}\text { PPPM cost } \\
\text { (US\$), } \\
\text { mean (SD) }\end{array}$} & \multicolumn{3}{|c|}{ RCl vs IVIg } & \multicolumn{3}{|c|}{$\mathrm{RCl}$ vs rituximab } & \multicolumn{3}{|c|}{$\begin{array}{c}\mathrm{RCl} \text { vs } \\
\text { IVlg+rituximab }\end{array}$} \\
\hline & $\begin{array}{c}\mathrm{RCl} \\
(\mathrm{N}=130)\end{array}$ & $\begin{array}{c}\text { IVlg } \\
(\mathrm{N}=390)\end{array}$ & $\begin{array}{c}P- \\
\text { value }\end{array}$ & $\begin{array}{c}\mathrm{RCl} \\
(\mathrm{N}=110)\end{array}$ & $\begin{array}{c}\text { Rituximab } \\
(\mathrm{N}=330)\end{array}$ & $\begin{array}{c}\boldsymbol{P} \text { - } \\
\text { value }\end{array}$ & $\begin{array}{c}\mathrm{RCl} \\
(\mathrm{N}=87)\end{array}$ & $\begin{array}{c}\mathrm{IVIg}+ \\
\text { rituximab } \\
(\mathrm{N}=87)\end{array}$ & $\begin{array}{c}P \text { - } \\
\text { value }\end{array}$ \\
\hline $\begin{array}{l}\text { Total visit } \\
\text { costs }\end{array}$ & $\begin{array}{c}\$ 2,126 \\
(\$ 5,585)\end{array}$ & $\begin{array}{c}\$ 3,964 \\
(\$ 8,531)\end{array}$ & $<0.001$ & $\begin{array}{l}\$ 2,008 \\
(\$ 5,950)\end{array}$ & $\begin{array}{c}\$ 2,607 \\
(\$ 5,885)\end{array}$ & 0.018 & $\begin{array}{c}\$ 1,234 \\
(\$ 1,915)\end{array}$ & $\begin{array}{c}\$ 4,858 \\
(\$ 13,688)\end{array}$ & $<0.001$ \\
\hline Hospitalization & $\begin{array}{c}\$ 874 \\
(\$ 5,083)\end{array}$ & $\begin{array}{c}\$ 1,764 \\
(\$ 7,788)\end{array}$ & $<0.001$ & $\begin{array}{c}\$ 932 \\
(\$ 5,479)\end{array}$ & $\begin{array}{c}\$ 993 \\
(\$ 4,244)\end{array}$ & 0.565 & $\begin{array}{c}\$ 319 \\
(\$ 1,322)\end{array}$ & $\begin{array}{c}\$ 2264 \\
(\$ 12,687)\end{array}$ & $<0.001$ \\
\hline $\begin{array}{l}\text { Non- } \\
\text { hospitalization }\end{array}$ & $\begin{array}{l}\$ 1,252 \\
(2,165)\end{array}$ & $\begin{array}{l}\$ 2,200 \\
(2,893)\end{array}$ & $<0.001$ & $\begin{array}{l}\$ 1,076 \\
(2,128)\end{array}$ & $\begin{array}{l}\$ 1,614 \\
(2,725)\end{array}$ & $<0.001$ & $\begin{array}{l}\$ 915 \\
(990)\end{array}$ & $\begin{array}{l}\$ 2,594 \\
(4,879)\end{array}$ & $<0.001$ \\
\hline
\end{tabular}

Figure 2 Average per-patient per-month total visit costs ${ }^{\mathrm{a}}$ in the post-index period.

Note: axcludes all medications

Abbreviations: PPPM, per-patient per-month; RCI, repository corticotropin injection; IVIg, intravenous immunoglobulin; SD, standard deviation.

patients within matched sets were restricted to the same follow-up time. The follow-up time was slightly lower in all three comparisons in the original analysis (RCI vs IVIg: 8.5 months vs 9.8 months; RCI vs rituximab: 8.7 months vs 9.7 months; RCI vs IVIg+R: 8.5 months vs 9.2 months). After censoring patients in each matched set to the shortest follow-up times, PPPM MRU and costs were similar to the original analysis (data not shown).

\section{Discussion}

This retrospective, observational study among DM/PM patients found that very few patients had received RCI $(\mathrm{n}=132)$, while the use of IVIg $(\mathrm{n}=1,150)$ or rituximab $(\mathrm{n}=562)$ was far more common. Compared to IVIg, RCI patients had fewer PPPM hospitalizations ( 0.09 vs 0.17 ; $P=0.049$ ), shorter LOS ( 3.24 days vs 4.55 days; $P=0.004$ ), PPPM HOPD visits $(0.60$ vs $1.39 ; P<0.001)$, and PPPM physician office visits ( 2.01 vs $2.33 ; P=0.035$ ). Compared to rituximab, RCI patients were associated with fewer PPPM HOPD visits $(0.56$ vs $0.92 ; P<0.001)$. Compared to IVIg+rituximab, RCI patients had shorter LOS (2.18 days vs 5.15 days; $P<0.001)$ and less PPPM HOPD visits $(0.53$ vs $1.26 ; P<0.001)$. Total non-medication PPPM costs were lower for RCI compared to IVIg $(\$ 2,126$ vs $\$ 3,964 ; P<0.001)$, rituximab ( $\$ 2,008$ vs $\$ 2,607 ; P=0.018)$, and IVIg+rituximab $(\$ 1,234$ vs $\$ 4,858 ; P<0.001)$.

To our knowledge, this is the first real-world study comparing alternative treatments for $\mathrm{DM} / \mathrm{PM}$ with respect to MRU and costs. Previous clinical studies have suggested the effectiveness and tolerability of RCI in DM/PM but did not include comparisons against other viable treatment options. ${ }^{17,18}$ Given the rarity of DM/PM, and of patients, this study includes a much larger sample size with at least $87 \mathrm{RCI}$ patients included in each comparison analysis, with the findings suggesting associations with RCI and less MRU in certain settings of care when compared with a matched population based on demographics and pre-index clinical characteristics receiving one of IVIg, rituximab, or IVIg+R. Patients in the RCI cohort, on average, had fewer hospitalizations, ER visits, HOPD visits, and physician office visits compared to those in the other three alternative treatment cohorts. HOPD visits were significantly lower in all three 
comparisons, presumably, partly due to the nature of administration of IVIg and rituximab, which are often administered in a HOPD setting. In a patient population associated with muscle weakness and loss of ambulatory movement, this finding is noteworthy because patients in the rituximab, IVIg, and IVIg+R cohorts have 1.6-2.4 times more HOPD visits in a given month. Annualized, this equates to roughly 6.4-7.2 visits for RCI patients compared to 11 for rituximab patients, 15.2 for IVIg+R patients, and 16.6 for IVIg patients.

Hospitalizations were also significantly less with a significantly shorter LOS for patients in the RCI cohort compared to those in the IVIg cohort, with an annualized average of almost one less hospitalization and 1.3 fewer days per hospitalization. Finally, patients in the RCI cohort had fewer physician office visits when compared to those in the IVIg cohort, which results in 3.8 fewer visits per year.

As a direct result of lesser MRU among RCI patients, total visit costs (hospitalization costs + non-hospitalization visit costs) were lower compared to the other alternative treatments. In the comparisons with the IVIg or IVIg+R cohorts, hospitalization costs were a key driver of total visit costs and were found to be significantly less in the RCI cohort. Among rituximab patients, hospitalization costs were similar to RCI patients, but non-hospitalization visit costs were the driver in total visit costs.

The target patient population in this study was found to be a very small proportion of all DM/PM patients, with only $6.1 \%$ of the DM/PM population receiving any of the alternative treatments examined. However, this is an important DM/PM patient population because they are complex in nature, may not tolerate initial therapeutic options, and can be difficult to manage. As expected, most patients in each of the study cohorts had previous treatment for DM/PM with either corticosteroids, azathioprine, methotrexate, or MMF, prior to initiating on alternative treatments (i.e., RCI, IVIg, or rituximab) in the year prior to initiating their respective alternative treatment. Reasons for discontinuation of previous therapies were not available in the claims data sources; however, based on current literature, ${ }^{8-10}$ it is possible that previous therapies were either not tolerated or insufficient in managing the symptoms of the disease. Furthermore, the cohorts were formed based on general clinical practice of using RCI as a later-line therapy with the potential for already having tried any of the above-mentioned treatments as well as IVIg and/or rituximab. These cohort selection criteria may bias against the RCI cohort, since the patients may have higher disease severity and/or longer time since diagnosis. We could not control for this bias because the claims did not have complete history of patients. Therefore, the estimates of differences between cohorts are expected to be conservative.

Given the low prevalence of DM/PM, this study was subject to relatively small sample sizes despite using three large data sources totaling $>450$ million covered lives. While the sample size is relatively small for a study of this type, the sampling methods used provided representativeness of the target population and sufficient power to detect differences between cohorts. It is the first study to examine and report on MRU and costs associated with the management of $\mathrm{DM} / \mathrm{PM}$ patients receiving RCI, IVIg, and/or rituximab using real-world data.

Additionally, while the retrospective nature of this study does not allow for the attribution of causality of outcomes, secondary real-world claims data can demonstrate important associations between treatment and MRU and direct costs. Other outcomes, such as indirect health-care costs, patient experience and health-related quality of life, and effectiveness, were not examined and might be considered for future studies.

\section{Conclusion}

Among patients with DM/PM in this study, very few had used RCI, an FDA-approved therapy, while the use of the off-label therapies of IVIg or rituximab was more common. After controlling for differences in baseline demographic and clinical characteristics between the alternative treatment cohorts, the RCI cohort was associated with significantly lower PPPM MRU in some settings than the IVIg, rituximab, and IVIg+R cohorts, which may suggest improved disease control. Associated total visit costs were also observed to be significantly lower for the RCI cohort than the IVIg and/ or rituximab cohorts $(23 \%-75 \%$ lower $)$. Cost differences were particularly notable in the inpatient setting, due to RCI use being associated with reductions in both the number of hospitalizations and LOS.

\section{Acknowledgment}

The authors take full responsibility for the content of and the decision to submit this article but thank Winnie Nelson of Mallinckrodt, LLC, for providing research and editorial support.

\section{Disclosure}

Mallinckrodt, LLC (Mallinckrodt), sponsored this research. Covance, Inc. (Covance), and Xcenda, LLC (Xcenda), received funding for this work. TK, TCB, and KA are employees of Covance which received funding for this research. MP and JWN are employees of Mallinckrodt. BP serves as a consultant for Xcenda which received funding for this research. Data for this study were presented in part at the 
American Society of Health-System Pharmacists Summer Meeting, June 11-15, 2016, in Baltimore, MD, USA. The authors report no other conflicts of interest in this work.

\section{References}

1. The Myositis Association. Dermatomyositis. Available from: http:// www.myositis.org/learn-about-myositis/types-of-myositis/dermatomyositis. Accessed April 27, 2016.

2. The Myositis Association. Polymyositis. Available from: http://www. myositis.org/learn-about-myositis/types-of-myositis/polymyositis. Accessed April 27, 2016.

3. Bradford Rice J, White A, Lopez A, et al. Healthcare resource utilization and work loss in dermatomyositis and polymyositis patients in a privately-insured US population. J Med Econ. 2016;19(7):649-654.

4. Bohan A. Clinical presentation and diagnosis of polymyositis and dermatomyositis. In: Dalakas MC, ed. Polymyositis and Dermatomyositis. Stoneham, MA: Butterworth Publishers; 1988:19-36.

5. Jacobson DL, Gange SJ, Rose NR, Graham NM. Epidemiology and estimated population burden of selected autoimmune diseases in the United States. Clin Immunol Immunopathol. 1997;84(3):223-243.

6. Bernatsky S, Joseph L, Pineau CA, et al. Estimating the prevalence of polymyositis and dermatomyositis from administrative data: age, sex and regional differences. Ann Rheum Dis. 2009;68(7):1192-1196.

7. The Myositis Association. Medications. Available from: http://www. myositis.org/learn-about-myositis/treatment/medications. Accessed April 27, 2016.

8. Dalakas MC. Immunotherapy of myositis: issues, concerns and future prospects. Nat Rev Rheumatol. 2010;6(3):129-137.

9. Dalakas MC. Inflammatory myopathies: management of steroid resistance. Curr Opin Neurol. 2011;24(5):457-462.

10. Lundberg I, Chung Y. Treatment and investigation of idiopathic inflammatory myopathies. Rheumatology (Oxford). 2000;39(1):7-17.

11. Levine TD. Rituximab in the treatment of dermatomyositis: an openlabel pilot study. Arthritis Rheum. 2005;52(2):601-607.

12. Oddis CV, Reed AM, Aggarwal R, et al. Rituximab in the treatment of refractory adult and juvenile dermatomyositis (DM) and adult polymyositis (PM) - the RIM Study [L13]. Presented at: American College of Rheumatology/Association of Rheumatology Health Professionals annual scientific meeting; November 6-10; 2010; Atlanta, GA.
13. Fasano S, Gordon P, Hajji R, Loyo E, Isenberg DA. Rituximab in the treatment of inflammatory myopathies: a review. Rheumatology (Oxford). 2017;56(1):26-36.

14. American Academy of Allergy, Asthma, and Immunology. Preparing for intravenous immunoglobulin (IVIG) infusion therapy. Available from: https://www.aaaai.org/conditions-and-treatments/ library/immune-deficiencies-library/ivig. Accessed September 7, 2016.

15. Rituxan ${ }^{\circledR}$. Rituximab prescribing information. Available from: http:// www.gene.com/download/pdf/rituxan_prescribing.pdf. Accessed September 7, 2016.

16. Rituxan ${ }^{\circledR}$. Rituximab for healthcare professionals. Available from: https://www.rituxanforra.com/patient/considering-treatment/infusions. html. Accessed September 7, 2016.

17. Levine T. Treating refractory dermatomyositis or polymyositis with adrenocorticotropic hormone gel: a retrospective case series. Drug Des Devel Ther. 2012;6:133-139.

18. Levine T, Malone J, Efthimiou P, et al. H.P. Acthar ${ }^{\circledR}$ gel in dermatomyositis and polymyositis treatment registry: an interim analysis. $J$ Neurol Disord. 2016;4:5.

19. Centers for Disease Control and Prevention. International Classification of Diseases, Ninth Revision, Clinical Modification (ICD-9-CM). Available from: http://www.cdc.gov/nchs/icd/icd $9 \mathrm{~cm} . h t m$. Accessed September 13, 2016.

20. Deyo RA, Cherkin DC, Ciol MA. Adapting a clinical comorbidity index for use with ICD-9-CM administrative databases. J Clin Epidemiol. 1992;45(6):613-619.

21. Elixhauser A, Steiner C, Harris DR, Coffey RM. Comorbidity measures for use with administrative data. Med Care. 1998;36(1):8-27.

22. Von Korff M, Wagner EH, Saunders K. A chronic disease score from automated pharmacy data. J Clin Epidemiol. 1992;45(2):197-203.

23. Parsons LS. Reducing bias in a propensity score matched-pair sample using greedy matching techniques. Proceedings of the Twenty-Sixth Annual SAS Users Group International Conference. Cary, NC: SAS Institute Inc; 2001; Paper 214-226.

24. Needham M, Mastaglia FL. Immunotherapies for immune-mediated myopathies: a current perspective. Neurotherapeutics. 2016;13(1): $132-146$.

25. Rosenbaum PR, Rubin DB. Constructing a control group using multivariate matched sampling methods that incorporate the propensity score. Am Stat. 1985;39(1):33-38.
ClinicoEconomics and Outcomes Research

\section{Publish your work in this journal}

ClinicoEconomics and Outcomes Research is an international, peerreviewed open-access journal focusing on health technology assessment, pharmacoeconomics and outcomes research in the areas of diagnosis, medical devices, and clinical, surgical and pharmacological intervention. The economic impact of health policy and health systems
Submit your manuscript here: https://www.dovepress.com/clinicoeconomics-and-outcomes-reserch-journal

organization also constitute important areas of coverage. The manuscript management system is completely online and includes a very quick and fair peer-review system, which is all easy to use. Visit http://www.dovepress.com/testimonials.php to read real quotes from published authors. 